Incision six inches long. Drainage-tube, catgut sutures, and styptic colloid dressing. Dressing removed in thirteen days, and whole line of incision soundly healed excert at its extreme points. Temperature normal throughout, except on one dav, when it was $101 \cdot 8^{\circ}$.

M. W-, aged fifty-eight (No. 30). - Same disease and similar treatment. Styptic removed in nine days, and onethird of line of incision found healed. Temperature normal throughout, except on one day, when it was $100^{\circ} 2^{\circ}$.

$$
\text { (To be continued.) }
$$

\section{PAUSES IN RESPIRATION.}

\section{BY WILLIAM O'NEILL, M.D., M.R.C.P. LOND.,} PHYSICIAN TO THE LINCOLN LUNATIC HOSPITAL, ETC.

Sont interesting cases which have lately been under my observation induce me to say a few words in reference to pauses in breathing. A pause in breathing is the most striking feature in that peculiar irregular breathing, marked by a series of ascending and descending respiratory acts, occasionally met with in some diseases of the heart and brain, and which was first noticed and described by the late Dr. Cheyne of Dublin, and subsequently by the late Dr. William Stokes of the same city. A case of "cerebral breathing" with nearly these characteristics presented itself to me a short time ago. The patient, who was suddenly attacked with apoplexy, became almost immediately coma. tose and paralysed on the right side. On the second day of her illness, on four or five occasions of about an hour's duration, the breathing assumed this form. The inspirations, which were of a blowing, almost of a whistling character, were about seven ascending and seven descending, the latter ending in the pause, which was usually about fifteen seconds in length.

What I wish, however, more especially to say is that the respiratory pause may be well marked, although the ascending and descending breathing acts may be more or less deficient, or even absent. Whether or not all those kinds of abnormal respiration which have a pause for their central phenomenon or symptom should be included under the category of Cheyne-Stokes respiration I am not prepared to say.

A lady who has suffered for several years from chronic bronchitis, emphysema of the lungs, great irregularity of the pulse, and hypertrophy, with dilatation of the right side of the heart, was attucked with an acute exacerbation of the chronic pulmonary affection in December of the past year. Edema of the ankles, which was generally present, rapidly increased, and in a few days the dropsy extended to the waist. After this the patient was unable to lie down, and, although very drowsy, she was afraid to go to sleep, for the moment she closed her eyes in sleep the breathing stopped, and was only renewed on her waking, which was generally after an interval of from twenty to thirty seconds. The apnoal state, followed by a succession of inspirations, gradually increasing in force, and ending in the ordinary dyspnoea of the patient, were the phenomena present in this case. The ascending series of inspirations were present, but the descending were absent. It would appear that the moment the watehful and controlling care of the will was withdrawn from the respiration by sleep the breathing stopped, from some cause or other acting on the medulla oblongata, and which had been kept in abeyance during the patient's waking moments; and respiration was, I think, only renewed by the intensity of the stimulus of the besoin de respirer, which roused her to the urgent necessity of breathing. The immediate cause of the pauses was temporary, for as soon as the chest symptoms began to improve and the dropsy to subside, so did the pauses begin to pass away.

A case almost similar to the preceding came under my care in 1878. The pauses were perhaps longer and the series of inspirations more distressing. So frightened was this man of the stopping of his breathing that for a few days before his death he kept his wife by his bedside in order to prevent him falling asleep.
But, as I have said before, the respi:atory pause may be present in a case without any other apparent deviation from the normal breathing. The patient may be respiring tranquilly and regularly when the pause occurs. He ends the act of breathing with an expiration, remains in a state of apnoea for a shorter or longer time, resumes breathing with an inspiration, and then goes on breathing naturally till another pause takes place.

I have seen two or three examples of this kind of respiration. Not long since I had a well-marked case of it under my care. A patient sixty years of age, who had always been a strong man, began to fall off in health and strength about ten or twelve months previously. His appetite failed, he gradually became thinner and paler, and suffered considerably from pains in his legs and soles of the feet. Latterly he complained of breathlessness and palpitations of the heart on exertion, of cedema of the ankles, of cough with a troublesome secretion of mucus in the throat, and of great depression of spirits and loss of sleep. On examination the lnngs, kidneys, and other organs of the body were healthy, with the exception of the heart, which had a weak impulse and showed some evidence of enlargement. There was no bruit to be heard in the præcordial region, but the first sound of the heart was short and rather indistinct, the second comparatively loud and clear. About ten days before this patient's death he "fainted" on rising in the morning, but when I saw him a short time afterwards he had not only recovered from the attack but seemed inclined to make light of it. That night he was delirious for the first and last time. The next day he was better and sitting up, but on the following day I noticed that he paused for a few seconds in breathing. The pauses, which were the only deviation from natural breathing, and which at first occurred every twenty or thirty minutes, gradually increased in length and frequency, and when at the longest their duration ranged from eighty to ninety seconds. This almost unprecedented length of the respiratory pause showed the large amount of earbonic acid necessary to accumulate in the capillaries of the lungs in order to produce stimulus sufficient to set the breathing going. The respirations in the intervals of the pauses were about eighteen in the minute, the pulse 80 in the minute, and the temperature of the body $98^{\circ}$. The pauses occurred both when the patient was asleep and awake, with, I believe, equal frequency, and were generally accompanied with more or less insensibility. The nurse and relations thought the pauses were the longest at night. I have seen the patient get out of bed with the assistance of the nurse to go to the nightchair, and on his way attacked with one of these trance-like seizures. I have shaken him and spoken londly to him in order to induce him to resume breathing, and although he moved his lips and made a slight effort to speak in response yet he did not respire for more than a minute. I have often felt the patient's pulse and examined his chest during the states of apnoea, but neither the strength, regularity, nor frequency of the pulse, nor action of the heart, was affected by them further than that I sometimes thought that the last eight or ten beats of the pulse were a little weaker, and a little more hurried than those which had preceded them The chest during the pauses was quite motionless, and nothing could be heard by auscultation but the sounds of the heart strangely reverberating through it. Accompanying the apncal attacks was a gradnally increasing aphonia which ended in a mere whisper, and a peculiarity of swal. lowing. The patient would take a mouthful of fluid, wait for a ininute or two and then gulp it down; the action of swallowing generally caused some coughing. The cough and secretion of mucus into the patient's throat during the early part of his illness were a source of great annoyance to him, but, from first to last, there was no appreciable inflammation or congestion of the lungs. I noticed that during the patient's waking hours he hardly ever wirked. 'The pupils of his eyes were apparently normal, the conjunctiva were congested, and occasionally he complained of iudistinctness of vision, and of flushes of light before his eyes. All through his illness, excepting when in a state of apncea, until about six hours before his death, he was sensible, and knew his relations and those about him. He sometimes complained of slight headache, and of uneasiness in the region of the heart and stomach. The pulse was regular, although weak, and never varied from 80 in the minute until the end was drawing near, when it became very feeble and quick. The breathing also towards the close was more rapid, the pauses were more frequent and shorter, and the temperature never exceeded $99^{\circ}$. 
Although no pust-mortem examination could be obtained, the pauses were, I think, the result of some lesion which not only affected the medulla oblongata, but also other parts of the nervous centres, as evidenced by the loss of voice and the difficulty of deglutition. The patient suffered most probably from fatty degeneration of the heart; and the fainting fit, which seemed to have ushered in his fatal illness, may have been one of the cerebral attacks sometimes seen in fatty disease of the heart. When I saw the patient soon after the fit I thought it might have been caused by embolism, and the subsequent symptoms lend some weight to that hasty opinion.

It has been said that hydrate of chloral is a very useful remedy in Cheyne-Stokes respiration. It so happened this patient had been taking hydrate of chloral when the respiratory pauses came on, and it was fully tried, but without any good result. The patient was ordered plenty of nutriment, and medicines of various kinds were prescribed; but the medicine from which he derived the greatest benefit was dilute nitric acid in a bitter infusion. This mixture sustained his strength, freed him from the troublesome throat mucus, and quite subdued the cough, thus rendering him more comfortable in his latter days. I tried the inhalation of nitrite of amyl with persistency in this and a similar case, but unfortunately with no apparent benefit. The nitrite of amyl inhalations may, however, be of use in Cheyne-Stokes respiration proper, where the ascending and descending rhythm of inspiration are well marked. The inhalations were of great use in a case of this kind which $I$ had under treatment more than five years ago. The patient suffered from intense renal dropsy with great orthopnoea, the breathing during the last few weeks of his life assuming wellmarked Cheyne-Stokes respiration. This patient derived much comfort and relief from time to time from the inhalation of four or five drops of the amyl. On several occasions it restored and reinvigorated the breathing when it was about cease.

The respiratory pause, it would seem, may be the result of either functional derangement or organic disease, but evidently more frequently the result of the latter. In these cases $I$ am of opinion that treatment, no matter how judicious, is of little or no avail ; for when this symptom sets in it is generally the precursor of dissolution. I might add that it is a most impressive symptom, and requires to be only once seen to be for ever remembered.

Lincoln.

\section{A CASE OF TRUE EASTERN LEPROSY.}

\section{BY JAMES STARTIN, M.R.C.S. ENG., \&e.}

TYPICAL cases of true Eastern leprosy of the anæsthetic variety are rarely seen in this country. The notes of the following case may be of much interest to the profession, especially as there is, at the present time, a considerable controversy going on as to the true etiology of the disease in this country and abroad, some authorities ascribing the cause to the eating of bad fish.

E. McG - aged forty-six, a native of Derbyshire, went out to India in 1858 at the age of twenty-three years with his regiment, and he remained out thirteen years. "His father and mother are both natives of Ireland, and there was no family history of syphilis or skin disease. The patient stated that he himself contracted syphilis whilst in India, and was cured there. He was vaccinated three times in India from natives, and twice at home, and he has not had small-pox. He came home to England about ten years ago. He then noticed, as he was on his way home, a slight mottling of the skin, and felt a numbness in the hands and arms, and a feeling of pricking as of pins and needles in the fingers and arms. He states he had plenty of food and very little fish, a few sardines and other tinned fish, but this he had only occasionally, and it was fresh. But he had no fresh vegetables fur some years. He had eaten a good deal of Indian corn made up as food at one time or another, and he does not attribute his disease to the eating of bad fish, as he says he had so little fish of any kind. He had had several bad attacks of ague and fever, which he said much weakened him, and he was often exposed very much to the climate.

When he first came under my notice he was covered with an eruption of brown maculæ or spots about the size of a sixpenny-piece, very slightly raised above the level of the surrounding skin. He had also patches of brawny brownsh skin quite insensible to a prick of a needle; in their centre, in different parts of the body, on the anterior surface of the bend of the elbows and forearm, were patches about eight inches long and three broad, also on the side of the neck, face, and ears, but smaller in size. The cutaneous nerves of the arm and forearm and the ulnar nerve could be seen and felt as tense and swollen cords, knotty and hard to the touch-a very characteristic and diagnostic feature in this disease, and being very well-marked in this case. He had also a tuberculous leprous-looking sore on the left leg on the inner side, about four inches below the knee-joint, and he had also a brown anæsthetic patch over the left knee. The next important feature of the disease was that of considerable wasting of the muscles between the thumb and index-finge and the intermetacarpal spaces, and he lost the power of adducting or closing his fingers, or even of holding any thing in his hands. A pail of water he would let fall trom want of power to keep his fingers closed. The outer side of the little-finger and hand was quite insensible to puncture with a needle. The patient complained of feeling much depressed at times. The mucous membrane of the mouth, tongue and lips was much affected with tuberculous patches, and very tender and sore at all times. At this period of the case I had a drawing taken of the patient, showing most of the features described. With regard to the treatment, I must say he has very much improved under the continued doses of chaulmoogra oil, taken first as an emulsion; then, as it returned very much, the capsules, of which he took as many as twenty a day; and he well rubbed the oil into the skin; he also took large doses of quinine, which he said he felt much better for.

He has now regained the use of his hands, and the anæsthetic patches are losing their insensibility, and the patient tells me that he feels much better and stronger, and the eruption is disappearing.

Now, with respect to diet, I ordered him, whilst he was in the hospital, a good diet, unstimulating, with plenty of fresh vegetables, which he much enjoyed, having had so little of them. As to the influence of bad fish as a common cause of origin of this disease, I confess I am very sceptical, this case in point of fact (and there could not be a more typical case, as was said by Sir Joseph Fayrer, Mr. Erichsen, Mr. Hutchinson, and several other eminent members of the profession, to whom $I$ had the pleasure of showing it at the Medical and Chirurgical and Pathological Societies) could not be possibly ascribed to the eating of bad fish, for he had none. But I do firmly believe that the want of fresh rege table food, and continued attacks of fever and ague destroying the nerve vitality, to be the principal causes of this case, and of others of leprosy. Most of the cases of this terrible disease occur in India, and, as I am reliably informed, the natives live almost on nothing, or whatever they can get, and it is amongst this class the disease is most prevalent. What can the supporters of the fish theory say to the fact that the natives on the borders of the great desert of Sahara never eat fish, and yet they get leprosy in its worst forms. And, again, the natives of Rawal-Pindi in the Punjab in India, and the natives who dwell on the Naga Hills in Assam, do not eat fish, and yet they get it too. Now the natives or the "Nuggs," who live in Arakan, live on fish, yet leprosy is seldom if ever seen among them. These and other important facts which I have elicited from reliable sources, from men who have seen many years' active service among the natives of India and Northern Africa, completely upset, in my opinion, the theory of the eating of bad fish as the origin of true leprosy. Neither do I believe leprosy to be a contagious disease.

Sackville-street, $\mathrm{w}$.

\section{DECALCIFIED BONE DRAINAGE-TUBES.}

\section{BY SURGEON SHIRLEY DEAKIN, F.R.C.S.ENG., I.M.D.}

IN an Indian station, far removed from surgical instrument makers, drainage-tubes are not often procurable, gutta-percha tubing even not being included among the articles of the small local store which does duty for a shop. Though native workmen are clever enough at copying an article from a pattern, they are very stupid in working from an engraving. Further, as regards bone drainage-tubes, all respectable Hindoos have serious caste objections to touching bones, so 